\title{
Assessing SDGs: A Methodology to Measure Sustainability
}

\author{
By Angela Delli Paoli* \& Felice Addeo ${ }^{\dagger}$
}

\begin{abstract}
Sustainable development is not a univocal concept and, subsequently, there is not a widespread-shared vision in the scientific community. From a general point of view, sustainable development could be considered as an attempt to combine growing concerns about environmental issues with socio-economic issues. Above all, sustainable development inspired the UN to build a Sustainable Development Goals (SDGs) program based on a set of indicators suggesting policies and actions to be implemented by Countries. Our paper deals with the concept of sustainable development at the basis of SDGs in order to clarify the SDGs conceptual framework, to establish a reliable research methodology for assessing such goals and to derive a composite SDG index. Using the latest national cross-country data available with multivariate statistics analysis, the study builds several composite indexes to assess European Member States performance on SDGs. The results show that the operational definition of the SDGs should be refined in order to improve its reliability. Thus, our paper could be seen as a starting point of what can be done to strengthen the scientific underpinning of sustainability indicators. Moreover, the study could be helpful to identify priorities and gaps that must be closed in order to achieve the SDGs. Results demonstrate that the SDGs are an action agenda for both high-income and low-income countries. Generally, the area where greater progress is required is gender equality, unemployment and sustainable agricultural systems.
\end{abstract}

Keywords: comparative analysis, composite indicators, factor analysis, SDGs indicators, SDGs, sustainability, sustainable development.

\section{Introduction}

Although sustainable development is a widely used concept, it has many different meanings and therefore provokes many different responses. In broad terms, the concept of sustainable development is an attempt to combine growing concerns about a range of environmental issues with socio-economic issues. It is embraced by big companies, social reformers, governments and environmental activists with different emphasis and interpretation on what sustainable development means. There is no shared vision. Thus, when examining an interpretation of sustainable development it is important to bear in mind the philosophy underlying the proponent's point of view, because this influences what are considered the main priorities and choices about what policies should be implemented and actions taken.

The paper focuses on the concept of sustainable development at the basis of

*Research Fellow, Department of Political, Social, and Communication Sciences, University of Salerno, Italy.

${ }^{\dagger}$ Assistant Professor, Department of Political, Social, and Communication Sciences, University of Salerno, Italy. 
the Sustainable Development Goals (SDGs) as defined by the European Commission through the EU SDGs indicators set with the aim to:

- understand the economic, social and environmental pillars of sustainable developments by defining them conceptually and operationally;

- provide a methodology for assessing each pillar and for building a composite SDG index;

- monitor how European Member States perform relatively to each pillar and to the overall index.

Thus, the paper addresses the following research questions.

RQ1: which countries will present major problems to meet SDGs and in which areas?

RQ2: how consistent are the social, environmental and economic dimensions of SDGs as defined by EU?

RQ3: how European Member States perform relatively to each of these dimensions?

The aim of the paper is twofold. On the one hand, we aim to clarify the conceptual framework at the basis of SDGs. On the other hand, we aim to propose a methodology for assessing SDGs able to go beyond single indicators without losing the information on single goals. This is done in 3 steps. First, by building a country level composite index for each SDG so to be able to measure SDG achievement across the 17 goals using the latest national cross-country data available. Second, by building pillar-based indexes across SDGs in order to theoretically identify the dimensions of the concept of sustainable development and operationally identify the most urgent priorities in each country. Third, by building an overall SDGs composite index to assess European Member States performance on SDGs.

Providing guidelines for actions by simultaneously viewing so many indicators can be very challenging. The aggregation of indicators into indexes at different levels and in a single composite measure helps to achieve a comprehensive assessment of sustainability.

The paper is organized as follows. The next two sections presents a literature review of the concept of sustainable development and a description of the SDGs. Then, research methodology (research design, data collection and data analysis techniques) is outlined. The following section presents the results in the $28 \mathrm{EU}$ Member States. Finally, limitations of the study and directions for future research are discussed and conclusions are drawn.

\section{The Concept of Sustainable Development}

According to the number of dimensions or pillars considered at the basis of sustainable development, we can distinguish four main approach to the concept: a 
one-pillar model, a three-pillar model (Littig and Grießler 2005), a multi-pillar model and an inter-pillar model (Murphy 2012: 19).

Historically the concept of sustainable development emerged in the context of environmental concerns in The World Charter for Nature (UN 1982) and further addressed with the aim to reconcile two seemingly contrasting paradigms: economic growth and protection of environment and natural resources (WCED 1987, UN 1992, Hák et al. 2016).

At this stage, the concept gives priority to the environmental and ecological dimension that is why this conceptualization can be defined as a one-pillar model. Within this perspective, sustainable development calls for a shift toward a more environmentally friendly way of life and equals to ecological sustainability coinciding with reducing production and use of harmful substances, minimizing environmental pollution, exploiting valuable resources. Obviously, this also have social implications and effects. Consider for example how lifestyles can affect the implementation of ecologically motivated control measures and reduce cultural resistance. However, here the focus is on ecological effects.

Following this, the World Summit on Social Development in Copenhagen in 1995 (UN 1995) stressed the importance of social-economic goals adding other pillars to the definition of sustainable development also endorsed by the World Summit on Sustainable Development in Johannesburg in 2002 (UN 2002). In the three-pillar model the social pillar receives prominent attention as clearly emerges from the Rio +20 outcome document "The Future We want" (UN 2012), which includes the mandate to elaborate the proposal on the SDGs. SDGs follow and expand the United Nations Millennium Development Goals (MDGs) which ended in 2015 and represent the most significant global effort to address sustainable development in a comprehensive way. Developed by UN member nations, these 17 goals and their 169 targets identify global development priorities, effectively defining sustainable development through the three pillars (Stevens and Kanie 2016).

According to this model, sustainable development should equally try to reach ecological, economic and social goals (Wichaisri and Sopadang 2017, DiazSarachaga et al. 2018).

The ecological pillar of sustainable development moves from the awareness that natural capital is becoming a limiting factor for current and future human activities. It aims to face severe ecological overuse, including rapid biodiversity loss, excessive nitrification, climate change, stock depletion leading to environmental degradations due to the ecosystems reduced ability to regenerate.

The economic pillar is concerned with maintaining the stocks of human man made capital, innovativeness and competitiveness needed to generate income in a period when - despite economic growth and increased welfare - there is a tendency of growing economic insecurity and vulnerabilities mainly due to decreased job growth, youth unemployment and low social security.

The social pillar remains the most conceptually elusive pillar in sustainable development discourse (Thin et al. 2002). While the concept of sustainable development (SD) generally refers to achieving a balance among the environmental, economic, and social pillars of sustainability, the meaning and 
associated objectives of the social pillar remain vague (Dempsey et al. 2011, Casula and Soneryd 2012). Difficulties regarding the identification of exclusively social issues rise as considerable overlaps exist across the pillars of sustainable development. These are particularly pronounced between economic and social pillars (Thin et al. 2002) as many themes deemed relevant to both dimensions (e.g. employment and unemployment). With the aim of defining the social dimension of sustainable development the concepts of social sustainability (Goodland 2002, Turkington and Sangster 2006, Chan and Lee 2008, Littig and Griessler 2005, Cuthill 2009, Dempsey et al. 2011) and social sustainable development have been discussed (Vavik and Keitsch 2010). Various social dimensions emerge from this literature. Littig and Grießler (2005) identify quality of life, social justice and social coherence as the social dimensions of sustainability. Chan and Lee (2008) detect social infrastructure, job opportunities, townscape design, preservation of local characteristics, psychological needs fulfillment as the factors fostering sustainability. Cuthill (2009) classifies social capital, social infrastructure social justice and engaged governance (participatory democracy) as promoting factors of social sustainability. Dempsey et al. (2011) identify two categories of social sustainability: social equity and sustainability of community, Vavik and Keitsch (2010) classify inclusion, access to education and participation as the three main goals of social sustainable development. In an attempt to provide a framework for policy analysis, Murphy (2012) proposes equity, awareness for sustainability, participation and social cohesion as the four social policy concepts.

The multi-pillar model originates from a growing concern about the threepillar model considered as overlooking other pillars of fundamental importance (Littig and Grießler 2005, Dahl 2012). The fourth pillar of sustainability has been alternatively identified in a cultural-aesthetic (Hawkes 2001, Nurse 2006, Barkin and Lemus 2012), political-institutional (Pfhal 2005, Spangenberg 2002, Spangenberg et al. 2002) or religious-spiritual dimensions (Clugston 2011, Hedlund-de Witt 2011). The cultural-aesthetic pillar is alternatively viewed as "cultural vitality", creativity, innovation (Hawkes 2001), shared identities, values, and beliefs (Nurse 2006). The political-institutional pillar is conceived as institutional orientations and mechanisms, which include norms and formal systems of rules and procedures (Spangenberg 2002, Spangenberg et al. 2002). The religious-spiritual pillar is rooted on the ground that ethical and moral values are essential to generating the transitions to sustainability (Clugston 2011, Hedlund-de Witt 2011).

The inter-pillar model originates from a call for developing greater inter-pillar linkages between the social, economic and environmental pillars (Dobson 2003, Littig and Grießler 2005, Gough et al. 2008, Diaz-Sarachaga, et al. 2018) and a need for reframing the three-pillar model by considering them as nested instead that as isolated dimensions (Kemp and Martnes 2007, Kemp et al. 2005, Murphy 2012, Holden et al. 2016). The division among the social, economic and environmental pillars is considered problematic because it posits the separation or even autonomy of economy, society and nature (Giddings et al. 2002) and their equal treatment is considered illusory as the economic dimension overshadows the other two dimensions (Helne and Hirvilammi 2015, Hák et al. 2016). To make 
just few examples the strong linkage between the social and economic pillars is visible in fiscal measures such as carbon taxes (designed to combat climate change) which can affect household income as energy prices increase (Scott 2007) exacerbating the effects of poverty. There are evident linkages also between the socio-environmental and economic pillars. Consider for example the relationship between the social goal of raising public awareness of sustainability issues through encouraging alternative, sustainable consumption patterns and green lifestyles and the economics of production patterns (Murphy 2012). The inter-pillar model asks for clarifying, conceptually and operationally, the linkages among the three pillars to make them compatible and coherent.

\section{The Sustainable Development Goals (SDGs)}

The SDGs succeed the Millennium Development goals (MDGs) as reference and universal guidepost for transiting to sustainable development in the period 2015-2030. Differently from the Millennium Development Goals, these goals are supposed to be universal, that is applicable to all countries, both developed and developing. The proposal comes in 2014 after a year of intergovernmental work of what was called the Open Working Group and after the decision taken at the RIO+20 Conference in the form of 17 goals (see Figure 1), with several targets under each goal, amounting to a total of 169 targets. The proposed goals and targets can be seen as a network, in which links among goals exist through targets that refer to multiple goals (Le Blanc 2015).

Figure 1. The SDGs

\section{SUSTAINABLE G
DEVELOPMENT}

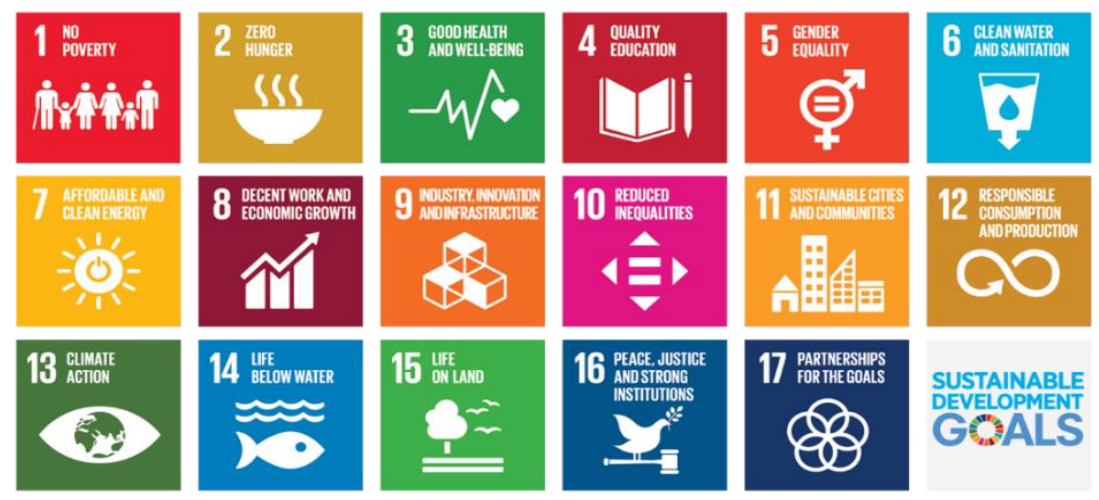

Source: https://bit.ly/2Ohq3F5.

The SDGs are supposed to be universally applicable, taking into account different national realities, capacities and levels of development and respecting national policies and priorities. Targets are defined as aspirational and global, with each government setting its own national targets guided by the global level of ambition but taking into account national circumstances. Each government will 
also decide how these aspirational and global targets should be incorporated in national planning processes, policies and strategies.

SDG1 End poverty in all its forms everywhere is aimed to eradicate extreme poverty, ensure that all men and women have equal rights to economic resources, as well as access to basic services, create sound policy frameworks at the national, regional and international levels, based on pro-poor and gendersensitive development strategies, to support accelerated investment in poverty eradication actions.

SDG 2 End hunger, achieve food security and improved nutrition and promote sustainable agriculture is aimed to ensure access by all people to safe, nutritious and sufficient food, end forms of malnutrition, double the agricultural productivity and incomes of small-scale food producers, ensure sustainable food production systems and implement resilient agricultural practices, maintain the genetic diversity of seeds, cultivated plants and farmed and domesticated animals and their related wild species.

SDG 3 Ensure healthy lives and promote well-being for all at all ages aims to reduce the global maternal mortality, neonatal and children mortality and mortality for illnesses from hazardous chemicals and air, water and soil pollution and contamination, the number of global deaths and injuries from road traffic accidents, to end the epidemics of AIDS, tuberculosis, malaria and neglected tropical diseases and combat hepatitis, water-borne diseases and other communicable diseases, to strengthen the prevention and treatment of substance abuse, to halve access to quality essential health-care services and to safe, effective, quality and affordable essential medicines and vaccines for all.

SDG 4 Ensure inclusive and equitable quality education and promote lifelong learning opportunities for all aims to ensure global literacy and numeracy, equitable and quality primary, secondary and tertiary education and effective learning outcomes, to increase the number of youth and adults who have relevant skills, including technical and vocational skills.

SDG 5 Achieve gender equality and empower all women and girls aims to end all forms of discrimination, violence, harmful practices (such as child, early and forced marriage and female genital mutilation) against women, ensure women's full and effective participation and equal opportunities for leadership at all levels of decision-making in political, economic and public life, recognize and value unpaid care and domestic work through the provision of public services, infrastructure and social protection policies.

SDG 6 Ensure availability and sustainable management of water and sanitation for all aims to increase access to safe and affordable drinking water, adequate and equitable sanitation and hygiene and end open defecation, improve water quality, address water scarcity.

SDG 7 Ensure access to affordable, reliable, sustainable and modern energy for all aims to increase the share of renewable energy and improve energy efficiency.

SDG 8 Promote sustained, inclusive and sustainable economic growth, full and productive employment and decent work for all aims to sustain per capita economic growth, achieve higher levels of economic productivity, support 
productive activities, decent job creation, entrepreneurship, creativity and innovation, reduce the proportion of youth not in employment, education or training (NEETs), protect labour rights and promote safe and secure working environments for all workers.

SDG 9 Build resilient infrastructure, promote inclusive and sustainable industrialization and foster innovation aims to enhance scientific research, upgrade the technological capabilities, encourage innovation and access to information and communications technology, upgrade infrastructures.

SDG 10 Reduce inequality within and among countries aims to reduce disparities in income growth within countries and reduce inequalities of outcome.

SDG 11 Make cities and human settlements inclusive, safe, resilient and sustainable aims to ensure access to adequate, safe and affordable housing and basic services, to safe, affordable, accessible and sustainable transport systems and enhance inclusive and sustainable urbanization by providing accessible green and public spaces and supporting positive economic, social and environmental links between urban, peri-urban and rural areas.

SDG 12 Ensure sustainable consumption and production patterns aims to encourage lifestyles in harmony with nature through sustainable and efficient use of natural resources, waste generation prevention, reduction, recycling and reuse, inefficient fossil-fuel subsidies rationalization.

SDG 13 Take urgent action to combat climate change and its impacts aims to strengthen resilience and adaptive capacity to climate-related hazards and natural disasters in all countries and integrate climate change measures into national policies, strategies and planning.

SDG 14 Conserve and sustainably use the oceans, seas and marine resources for sustainable development aims to prevent and significantly reduce marine pollution, manage and protect marine and coastal ecosystems, minimize and address the impacts of ocean acidification, effectively regulate harvesting and end overfishing.

SDG 15 Protect, restore and promote sustainable use of terrestrial ecosystems, sustainably manage forests, combat desertification, and halt and reverse land degradation and halt biodiversity loss aims to promote the implementation of sustainable management of all types of forests, halt deforestation, restore degraded forests, land and soils, combat desertification, ensure the conservation of mountain ecosystems, reduce the degradation of natural habitats.

SDG 16 Promote peaceful and inclusive societies for sustainable development, provide access to justice for all and build effective, accountable and inclusive institutions at all levels aims to promote the rule of law at the national and international levels, ensure equal access to justice, strengthen the recovery and return of stolen assets and combat all forms of organized crime, reduce corruption.

SDG 17 Strengthen the means of implementation and revitalize the global partnership for sustainable development aims to strengthen international cooperation on education, science, technology and innovation and domestic resource mobilization including through support and development assistance 
commitments to developing countries.

\section{Methodology}

The literature review on the concept of sustainable development showed that there is no clear and shared conceptual and operational definition of this concept. Above all, the operational definitions of the social, environmental and economic dimensions have been proved to be tricky and this may harm their validity.

These considerations inspired our research design, whose aim is twofold: clarify the conceptual framework at the basis of SDGs and establish a methodology for assessing SDGs able to go beyond single indicators without losing the information on single goals.

These goals have been addressed in three steps.

1. creating a composite index for each SDG to measure SDG achievement across the 17 goals;

2. basing on the results of the step 1, exploring the social, environmental and economic dimensions of SDGs as defined by EU with the aim to synthesize them in three indexes, each one representing a pillar;

3. developing an overall SDGs composite index to assess EU members' general performance.

Starting from the main research goals, the relevant objectives were pursued and translated into the following research questions:

RQ1: which countries will present major problems to meet SDGs and in which areas?

RQ2: how consistent are the social, environmental and economic dimensions of SDGs as defined by EU?

RQ3: how European Member States perform relatively to each of these dimensions?

Research unit of analysis are the 28 EU Member States.

Data were collected from the official EUROSTAT 17 SDGs set, using the most recently updated source for each indicator. We selected those indicators offering data for at least $90 \%$ of Member States. This criterion led us to select 102 indicators and to discard SDG6 and SDG14 because there were too many missing values for the majority of their indicators.

Data analysis articulates into 4 steps:

1. building a composite index for each SDG;

2. aggregating SDGs according to the social, economic and environmental pillar;

3. building a composite index for each pillar;

4. building an overall composite SDG index. 
The creation of the composite indexes followed a two-stage Principal Component Analysis approach (Di Franco and Marradi 2013). This procedure was applied both for building goal-based indexes, pillar-based indexes and the overall SDG index.

In the first stage the whole set of indicators was analysed in order to single out meaningful clusters of variables. In the second stage, a new principal component analysis was performed with the variables showing the highest loadings. The procedure ended when only one component was extracted which synthesises the greatest part of the total variance and the greatest number of variables with high loadings. Figure 2 represents the procedure presenting the example of the SDG 1.

Figure 2. Two-stage Principal Component Analysis

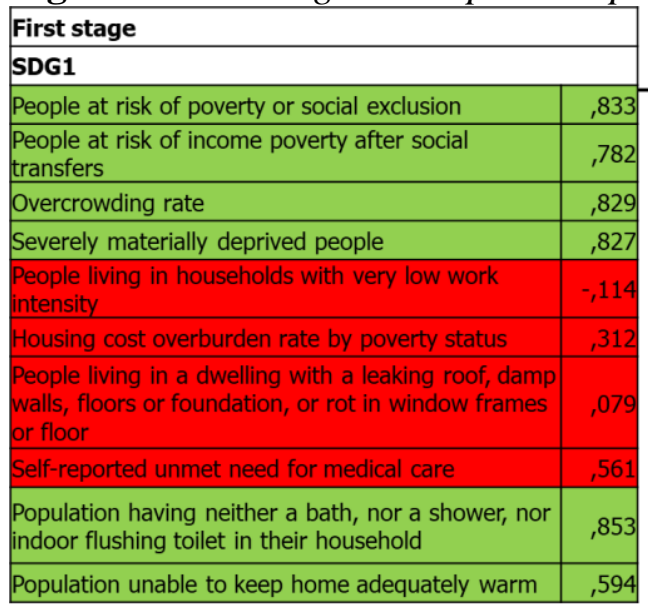

\begin{tabular}{|l|r|}
\hline Second Stage \\
\hline SDG1 \\
\hline People at risk of poverty or social exclusion &, 966 \\
\hline $\begin{array}{l}\text { People at risk of income poverty after social } \\
\text { transfers }\end{array}$ &, 841 \\
\hline Overcrowding rate &, 719 \\
\hline Severely materially deprived people &, 939 \\
\hline $\begin{array}{l}\text { Population having neither a bath, nor a shower, } \\
\text { nor indoor flushing toilet in their household }\end{array}$ &, 754 \\
\hline Population unable to keep home adequately warm &, 801 \\
\hline
\end{tabular}

Source: Authors' Elaboration.

In order to aggregate SDGs according to the social, economic and environmental pillars, we looked at the direct impacts and policy goals of SDGs.

Thus, those SDGs with social direct impacts were aggregated into the social pillar, those with economic direct impacts and goals were aggregated into the economic pillar, those with ecological direct impacts and goals were aggregated into the environmental pillar (see Figure 3). 
Figure 3. The Aggregation of SDGs into the Three Pillars

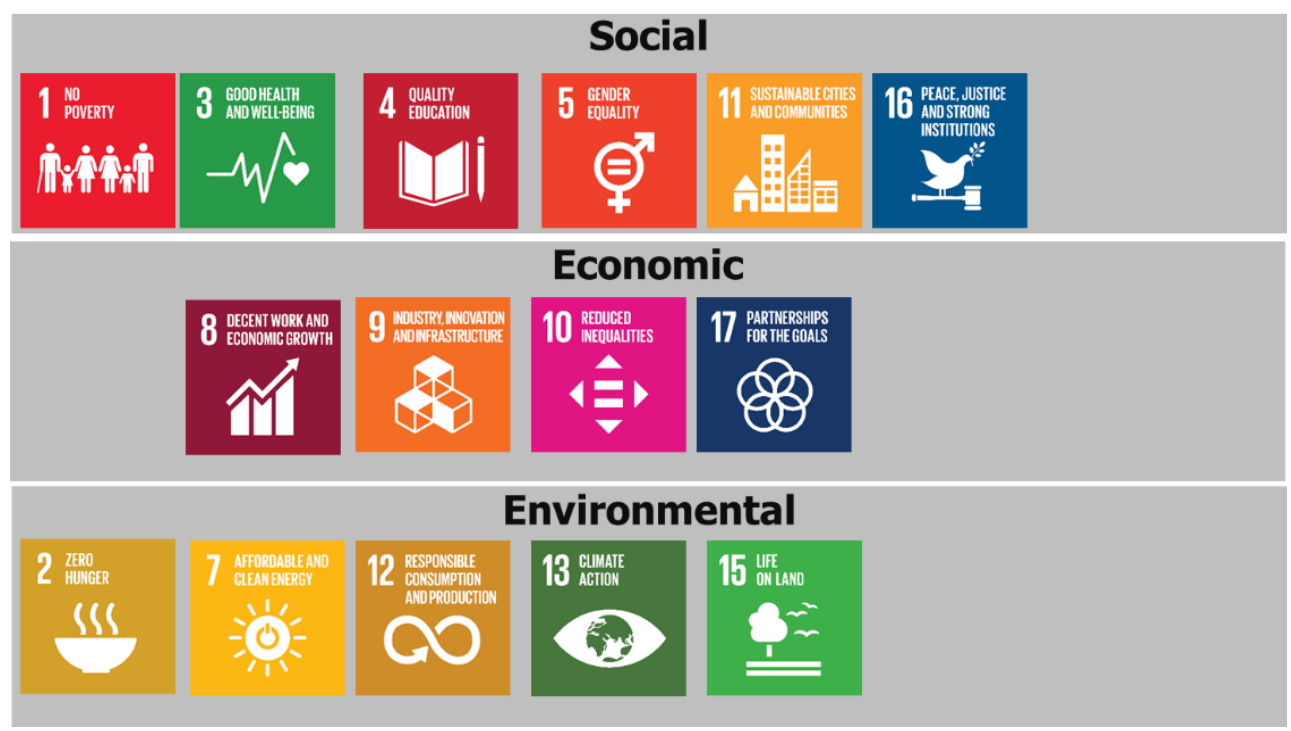

Source: Authors’ Elaboration.

The semantic polarity of some indexes was inverted to make them more legible. For each country, we then created an adjusted indicator score that lies between 0 and 100. This adjusted indicator score marks the placement of the country between the worst (0) and best cases (100).

\section{Findings}

By applying the two-stage Principal Component Analysis to each SDG, we calculated a country score for each of the 17 goals.

The scores range between the worst position (0) and the best one (100). In addition, we analyzed the role of different welfare regimes in coping with financial crisis. Expanding the Esping-Andersen' proposition (1990), we divided the 28 countries in five different welfare regimes (see also Ferrera 1996).

RQ1: Which Countries will Present Major Problems to meet SDGs and in which Areas?

Central and Eastern European Countries are bad performer in relation to SDG 1 indicating that extreme poverty still represents a major problem in these countries. In relation to the other European Countries, social-democratic and continental countries are the best performers indicating that in these countries poverty is not a major challenge. On the contrary, SDG 2 which is mainly based on sustainable agriculture represents a major challenge for most countries both Liberal (in particular United Kingdom and Luxembourg), Continental (in particular Germany, Belgium), Social Democratic (in particular Netherlands) and Southern European countries (in particular Cyprus and Malta) showing that many countries need to shift toward more environmentally sustainable agricultural 
practices. The low performance of SDG 3 which is concerned with health and well-being is concentrated in Central and Easter European countries with Lithuania, Latvia and Romania as worst performers. The quality of education SDG 4 - is higher in Social Democratic and Continental countries and lower in Southern European (Greece and Italy in particular) and Central and Southern European countries (Bulgaria and Romania in particular). Gender equality - SDG 5 - does not show a geographical pattern as - apart from being low in the poorest countries (in particular Romania, Malta, Cyprus, Greece) - is low also in some of the richest countries such as United Kingdom, and Luxembourg. Energy - SDG 7 - represents a major challenge in most countries showing that Southern and Eastern countries (particularly, Bulgaria, Lithuania, Cyprus, Portugal Greece, Romania, Spain, Italy and Malta) need to shift their energy systems from highcarbon to low-carbon primary energy in order to fulfil SDGs 7. With reference to employment and decent work - SDG 8 - there is a clear division between the Social-Democratic, Liberal and Continental countries on the one hand and the Southern and Central and Eastern European countries on the one hand. The best performers are Sweden, Luxembourg, Denmark and Germany; the worst performers are Greece, Spain, Croatia and Italy. Research and Innovation - SDG 9 - appears to be a major challenge in most of the countries with the exemption of Sweden, Denmark, Finland and Germany that show the best scores. Income inequality - SDG 10 - seems to be concentrated in Southern and Eastern Europe with Bulgaria, Romania, Lithuania, Spain, Latvia, Greece, Estonia and Italy as worst performers. Czech Republic, Slovakia, Finland, Slovenia and Netherlands show a better performance than the other European countries. City sustainability and security - SDG 11 - is higher in Sweden, Germany, Ireland, Netherlands, United Kingdom and Denmark while being a concerning issue in Bulgaria, Romania, Croatia, Poland, Latvia, Greece, Hungary, Slovakia, Cyprus, Lithuania, Czech Republic and Italy. There are major challenges across the countries in meeting SDGs 12 (sustainable consumption and production): some of the Southern countries perform well on this SDG (Greece, Malta, Portugal, Croatia and Italy in particular) which instead seems to represent and urgent issue for the majority of the countries. Actions against climate change (SDG 13) and in favour of land sustainability (SDG 15) appear to be more effective in some Central and Eastern European countries such as Estonia, Latvia, Lithuania, Romania, Bulgaria and Estonia than in Liberal, Continental and Southern European countries. Some of the Social Democratic countries such as Netherlands and Denmark are among the worst performers on climate actions.

Justice - SDG 16 - does not represent a problem in Continental, Liberal and Social-Democratic countries (with Luxembourg, Germany and United Kingdom as best performers) whereas it represents a major challenge in almost all the Southern, Central and Eastern European countries (with Bulgaria, Slovakia and Croatia showing the poorest rating).

A large number of European countries face major challenges in achieving SDG 17 - which is related to the means of implementation targets and includes engagements in supporting implementation of all the goals - largely because of their insufficient financial contributions towards international development 
cooperation. Netherlands and Germany show the highest rating while the other countries show a low rating.

RQ2: How Consistent are the Social, Environmental and Economic Dimensions of SDGs as Defined by EU?

In order to represent the performance of the European Member States on the three pillars we have built thematic cartographies for each pillar.

The cartographies show:

- the overall score on the pillars in 5 classes represented by the colour of the countries

- The dark green band is bounded by the maximum scoring;

- The light green band represents the good performers;

- The yellow band represents an intermediate scoring denoting significant challenges in achieving the SDGs;

- The red band describes cases where major challenges must be overcome to achieve the SDGs.

- the score on each SDGs which compose the specific pillar (SDGs 3, 4, 5, 11 and 16 for the social pillar; SDGs 8, 9, 10 and 17 for the economic pillar; SDGs 2, 7, 12, 13 and 15 for the environmental pillar). These scores are represented by the bar charts.

Starting from the economic pillar, as you can see from figure 4 , the cartography is split into two parts dividing the richer countries (Social-Democratic, Liberal and Continental countries) from the poorer ones (Southern, Central and Eastern countries). This does not mean that highly-ranked countries have achieved the SDGs. As you can see from the bar charts and as we have highlighted in the previous discussion, some of the best performers also score low in relation to some SDGs. It is the case of SDG 17 - partnership for the goals - which represents a major problem both for the richest and the poorest countries and of SDG 9 industry, innovation and infrastructure - which scores low also in countries with a good economic performance (such as the Czech Republic). 
Figure 4. The Economic Index

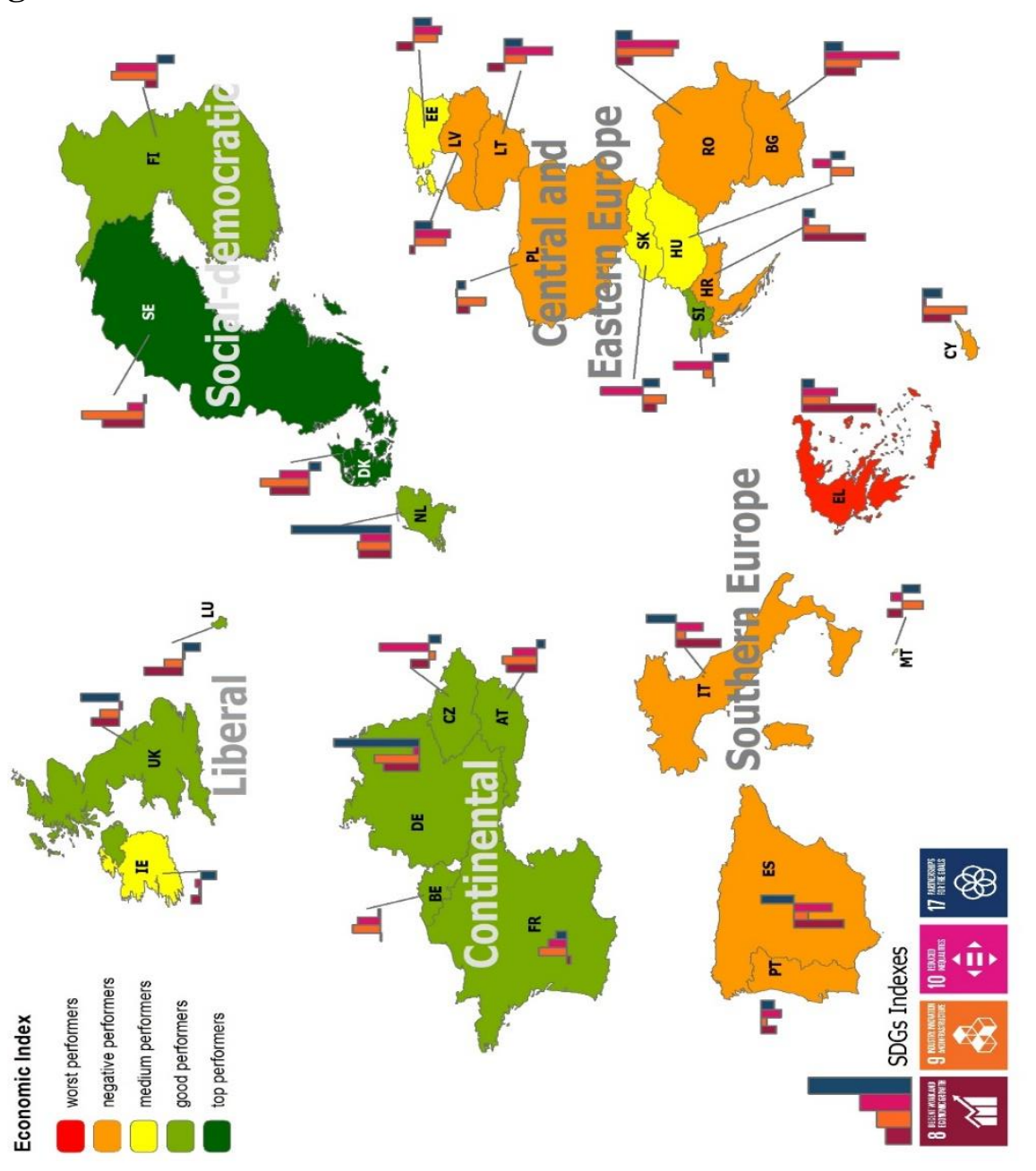

Source: Authors' Elaboration.

Social sustainability is more pronounced among the richest countries (Figure 5). The social pillar performs similarly to the economic pillar, with SocialDemocratic, Liberal and Continental countries performing better than the others. As in the economic pillar case, also among the best performers some social gaps remain to be filled. This demonstrates that neither the richest countries are completely ready for SDGs. Even these relative top performers have their work cut out. For instance, gender equality remains an issue both for rich and for poor countries. On the other hand, some of the lower-scoring countries score good on SDG 3 - Health and well-being - and on some local priorities such as SDG 11 sustainable cities and communities. 
Figure 5.The Social Index

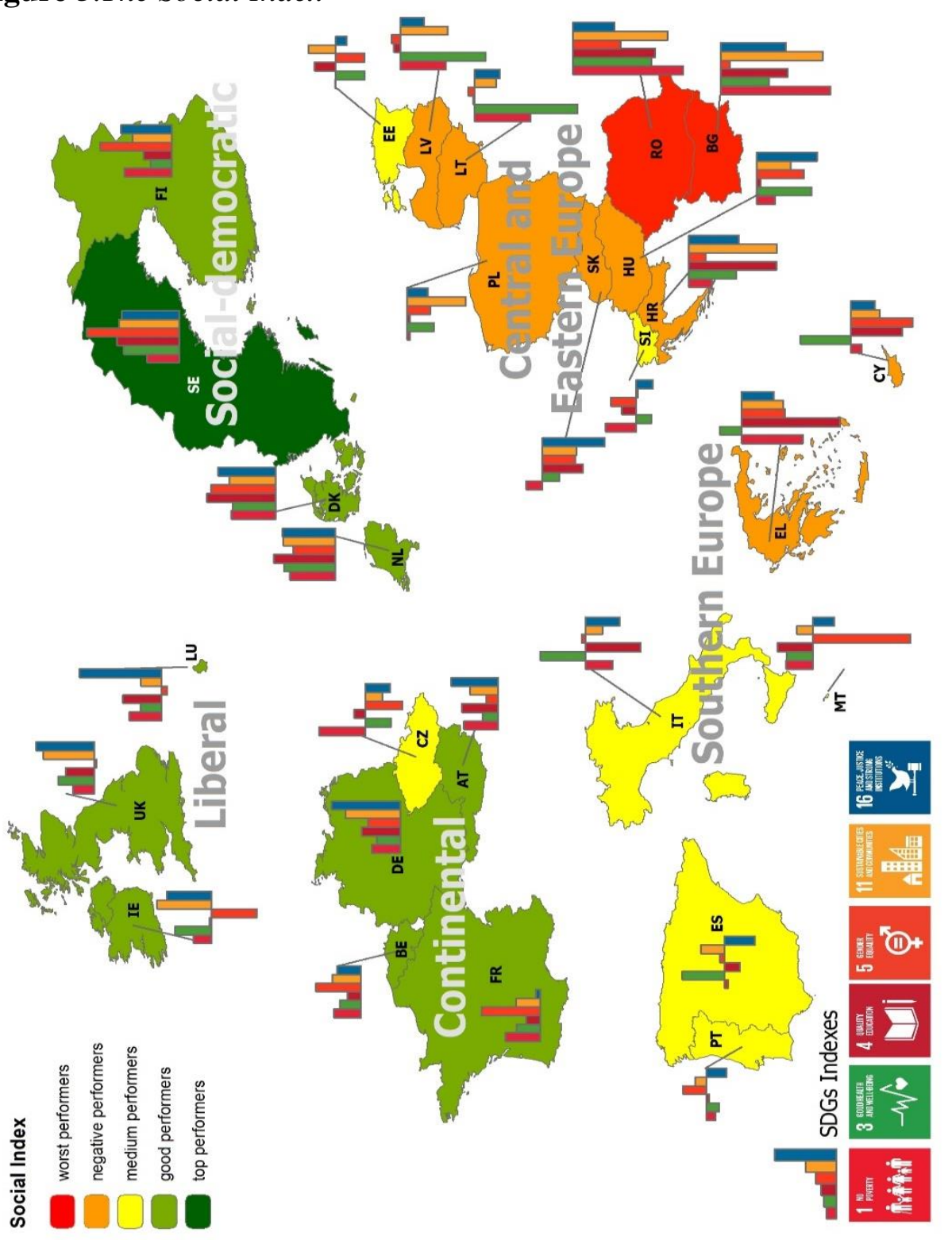

Source: Authors' Elaboration.

Turning to the environmental pillar, the results are quite mixed up (Figure 6). While for the previous two pillars for most of the economic and social priorities, higher income countries demonstrate to perform better than lower-income countries; richest countries perform worse on environmental priorities. It is the case of Netherlands, United Kingdom, Belgium, Denmark. The majority of countries face significant challenges about environmental issues but the causes of these performances vary. The worst performers are the Liberal and some Southern countries whereas the best performers are the Social-Democratic countries. The SDGs responsible for the performance are different. Estonia, which has a very good performance on 3 out of 4 environmental SDGs, shows a negative performance on SDG 12. This is the case also of Sweden and Finland. 
Figure 6. The Environmental Index
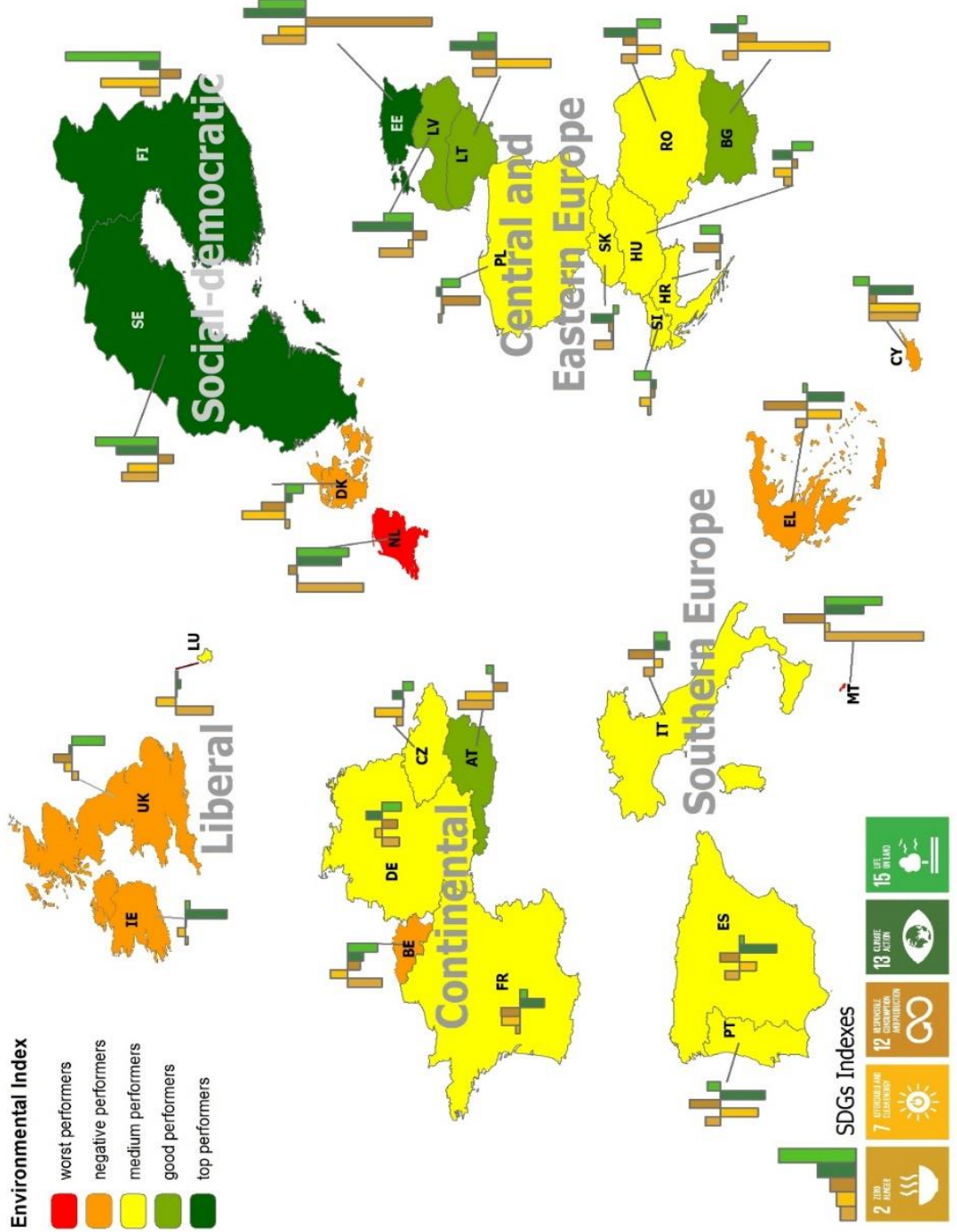

Source: Authors' Elaboration.

RQ3: How European Member States Perform Relatively to each of these Dimensions?

Results on the composite SDG index (Figure 7 and 8) demonstrate that the SDGs are an action agenda for rich countries as well as developing countries. Every country faces major challenges as indicated by the large number of red, orange and yellow countries in Figure 7. 
Figure 7. The Overall SDG Index

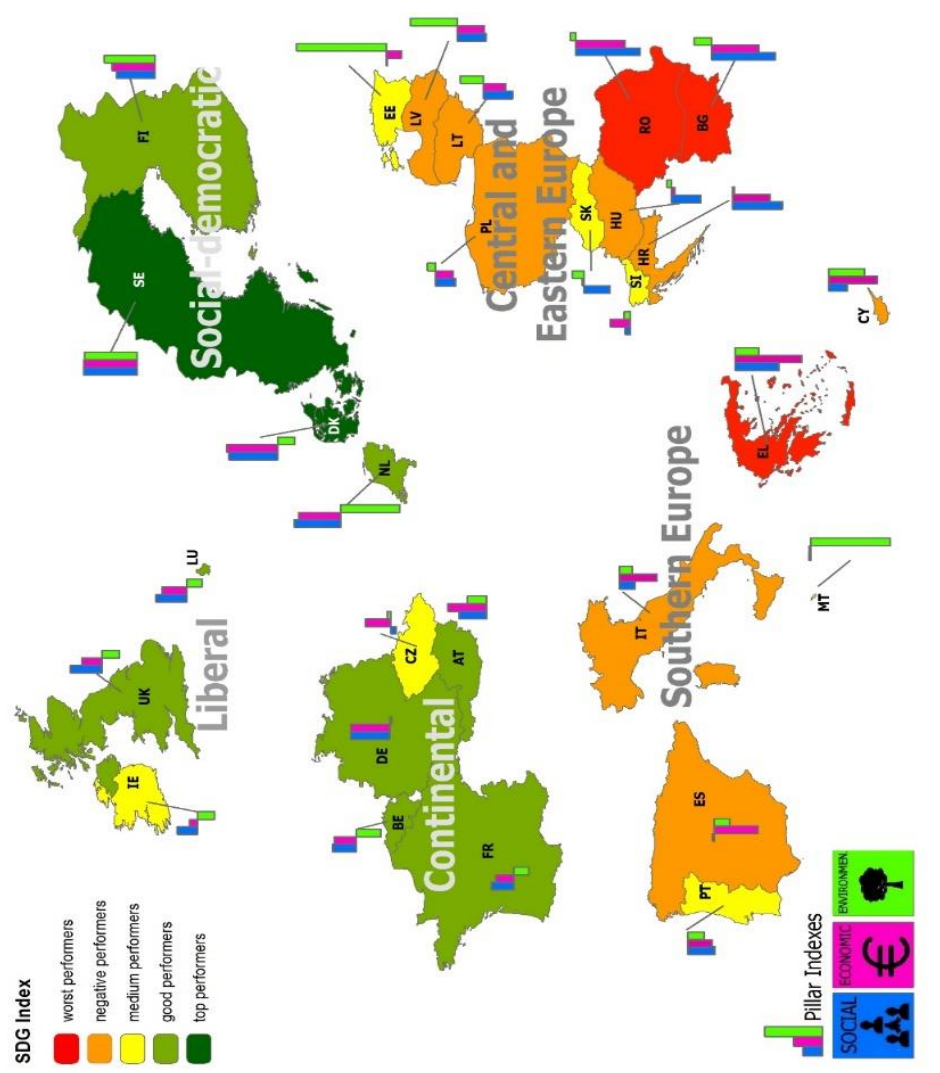

Source: Authors' Elaboration.

By looking at the pillar-based indexes showed in bar charts of Figure 7, the greatest challenges exist on environment and particularly, as we have previously seen, on responsible consumption and production and sustainable agriculture. Even many high-income countries fall far short of achieving the SDGs. Generally, the area where greater progress is required is gender equality where we have seen major shortfalls, unemployment and sustainable agricultural systems. It is not surprising that the poorest countries tend to be near the bottom of the ranking.

Higher-income countries tend to perform better on most economic and social SDG priorities but some of them perform worse on environmental indicators. It is possible to be rich (high income) but with significant inequality and unsustainable environmental practices. However, this is not as evident on the final SDG performance as these indicators represent a modest share of SDG priorities.

Richer countries face more specific but nonetheless major challenges in areas such as climate change mitigation, inequality, sustaining the global partnership, and targeted challenges in areas such as nutrition, gender equality, or education. 
Figure 8. The Performance of EU Member States on the SDG Index

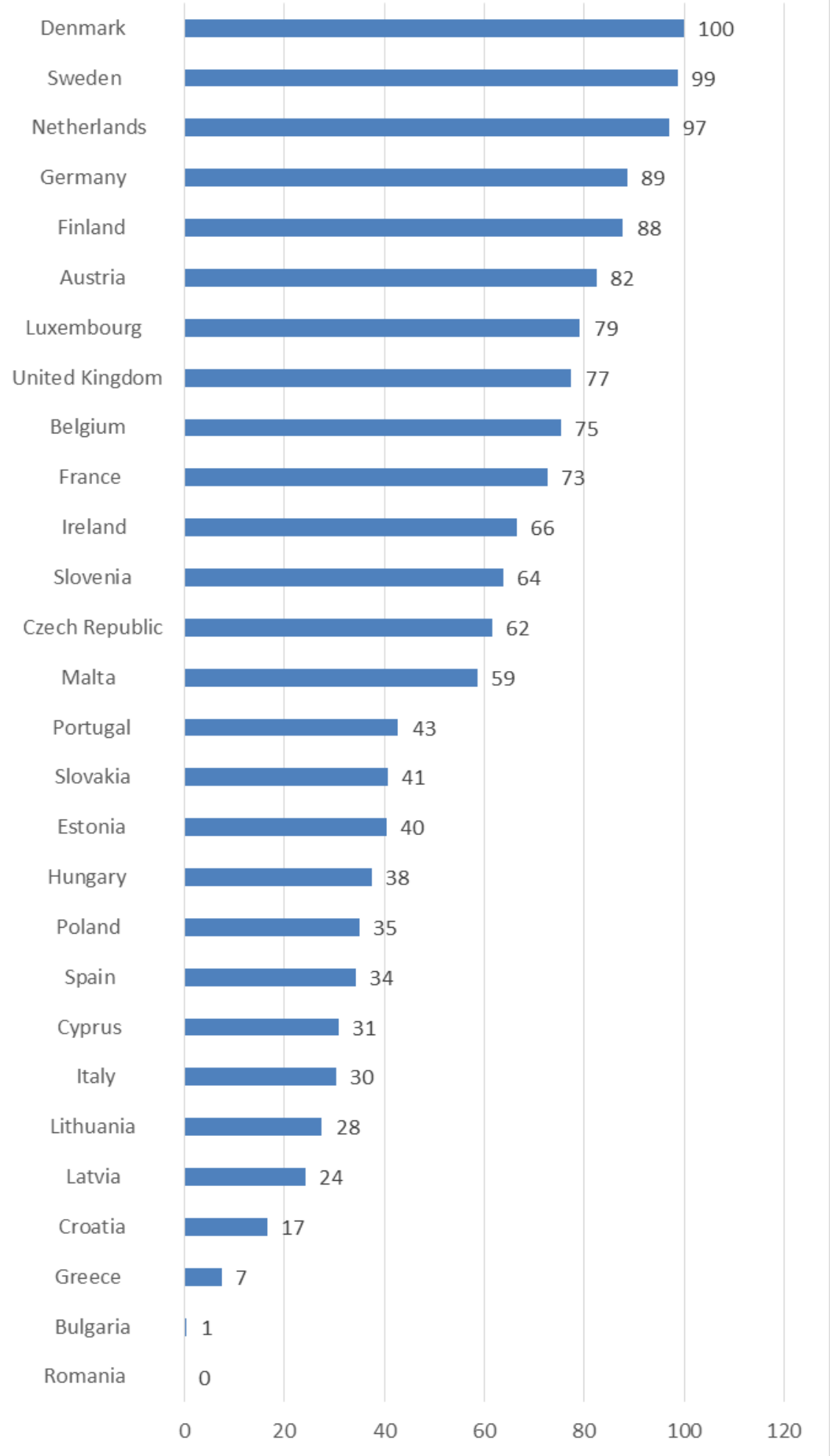

Source: authors' elaboration. 


\section{Limitations, Discussion and Conclusions}

The study aimed to propose a method for comprehensively assessing SDGs.

By assessing single SDGs, aggregating them into conceptual pillars and presenting an overall SDG index, it demonstrates that SDGs are an action agenda both for high-income and low-income countries. Generally, the social and economic pillars are quite aligned whereas the environmental pillar is disconnected from the social and economic ones.

This may indicate a misalignment between socio-economic and environmental policies that needs further investigation. Moreover, this may indicate that some trade-offs may occur across SDGs. Progress on one pillar such as the economic or social goals cannot fully offset lack of progress on another (e.g. rising environmental degradation). Obviously, this may have some implications on the general framework implying a reframing of the UN paradigm of three pillars of sustainable development as each other independent and asking for conceptualizing them as a nested system both conceptually and operationally.

This misalignment can also be explained referring to the level of analysis of sustainability: part of the problem is that sustainability cannot be addressed solely at the national level as complex interactions among political and governmental levels in complex nested subsystems affect it.

The implications of the study are disparate.

From a conceptual point of view, the study may help to clarify the policy goals of each pillar and detect not valid and/or missing indicators. It is the case of the social pillar where the social capital, social inclusion and participative dimensions is missing.

More generally, as already underlined (Dahl 2012: 15), present indicators address the "hardware" of national sustainability as they measure the status of environmental, social and economic parameters but they do not assess the "software" meant as the processes of decision-making, which support progress toward a sustainable system.

From an operational point of view, it helps to:

- identify unreliable or disconnected indicators for each SDG: it is the case of the indicators reported in Table 1. From this perspective, the paper can feed the discussion on the need of relevant indicators for monitoring SDGs (Riley 2001, Morse 2013, Dahl 2012, Hák et al. 2016). It provides a starting point of what can be done to strengthen the scientific underpinning of sustainability indicators;

- identify a methodology for monitoring SDGs over the years. A longitudinal analysis of SDGs performance over the year, updated and reported regularly, can provide clear signals on the success or failure of national policy initiatives and actions. 
Table 1. Disconnected Indicators

\begin{tabular}{|c|c|}
\hline SDG & Indicator \\
\hline 1 & People living in households with very low work intensity \\
\hline 1 & Housing cost overburden rate by poverty status \\
\hline 1 & $\begin{array}{l}\text { People living in a dwelling with a leaking roof, damp walls, floors or foundation, } \\
\text { or rot in window frames or floor }\end{array}$ \\
\hline 2 & Obesity rate by body mass index (BMI) \\
\hline 2 & Government support to agricultural research and development \\
\hline 2 & Agricultural factor income per annual work unit (AWU) (source: EC services) \\
\hline 3 & Smoking Prevalence \\
\hline 3 & Self-reported unmet need for medical care \\
\hline 3 & $\begin{array}{l}\text { Population living in households considering that they suffer from noise, by } \\
\text { poverty status }\end{array}$ \\
\hline 4 & Early leavers from education and training by sex \\
\hline 4 & Tertiary educational attainment \\
\hline 5 & Gender pay gap \\
\hline 5 & Early leavers from education and training GAP Males-Females \\
\hline 5 & Employment rates of recent graduates GAP Males-Females \\
\hline 5 & Tertiary educational attainment GAP Males-Females \\
\hline 7 & Primary energy consumption_100 $=2005$ \\
\hline 7 & Final energy consumption Index \\
\hline 7 & Share of renewable energy in gross final energy consumption by sector \\
\hline 7 & Energy dependence by product \\
\hline 7 & Energy productivity \\
\hline 8 & People killed in accidents at work \\
\hline 8 & Resource productivity INDEX \\
\hline 9 & Average $\mathrm{CO} 2$ emissions per km from new passenger cars \\
\hline 10 & Purchasing power adjusted GDP per capita \\
\hline 10 & Relative median at-risk-of-poverty gap \\
\hline 10 & Number of first time asylum applications (total and accepted) per capita \\
\hline 10 & EU financing for developing countries \\
\hline 10 & EU Imports from developing countries \\
\hline 11 & $\begin{array}{l}\text { Population living in households considering that they suffer from noise, by } \\
\text { poverty status }\end{array}$ \\
\hline 11 & $\begin{array}{l}\text { Distribution of population by level of difficulty in accessing public transport (Very } \\
\text { High }+ \text { High) }\end{array}$ \\
\hline 11 & $\begin{array}{l}\text { People living in a dwelling with a leaking roof, damp walls, floors or foundation, } \\
\text { or rot in window frames or floor }\end{array}$ \\
\hline 11 & Artificial land cover per capita (artificial land) \\
\hline 11 & $\begin{array}{l}\text { Share of population which reported occurrence of crime, violence or vandalism in } \\
\text { their area }\end{array}$ \\
\hline 11 & Change in artificial land cover \\
\hline 12 & Resource productivity INDEX \\
\hline 12 & Volume of freight transport relative to GDP \\
\hline 12 & Recycling and landfill rate of waste excluding major mineral wastes \\
\hline 12 & Final energy consumption index \\
\hline 12 & Energy productivity \\
\hline 12 & Share of renewable energy in gross final energy consumption by sector \\
\hline 13 & Greenhouse gas emissions intensity of energy consumption \\
\hline
\end{tabular}




\begin{tabular}{|l|l|}
13 & $\begin{array}{l}\text { Contribution to the } 100 \mathrm{bn} \text { international commitment on climate related expending } \\
\text { (public finance) }\end{array}$ \\
\hline 13 & Primary energy consumption_100 $=2005$ \\
\hline 13 & Final energy consumption inDEX \\
\hline 15 & Sufficiency of terrestrial sites designated under the EU habitats directive \\
\hline 15 & Change in artificial land cover \\
\hline 15 & Estimated soil erosion by water \\
\hline 16 & Death due to homicide, assault, by sex \\
\hline 16 & $\begin{array}{l}\text { Share of population which reported occurence of crime, violence or vandalism in } \\
\text { their area }\end{array}$ \\
\hline 16 & Physical and sexual violence to women experienced \\
\hline 17 & Level of citizens' confidence in EU institutions \\
\hline 17 & Official development assistance as share of gross national income \\
\hline 17 & Shares of environmental and labour taxes in total tax revenues \\
\hline
\end{tabular}

Source: Authors' elaboration.

From a policy point of view, the study can be helpful to identify priorities for early action, understand implementation challenges and detect gaps that must be closed in order to achieve the SDGs.

The study also presents some limitations. First, it uses the most recent available data for each indicator and does not take into account historical data since the availability of such time series is too limited for some variables. As a result, the goal indexes, the pillar indexes and the overall SDG tell us where a country currently stands on each of the indicators considered, but they cannot be used to infer how fast countries have been progressing towards achieving the SDGs.

Second, the study leverages on data of different quality for the different countries. Some countries have missing data on some of the indicators, misclassification and out-of-date assessment. Filling these gaps will require improved metrics that would imply to invest in strengthening data collection and statistical capacity in all countries.

Third, the study ranks countries relative to other countries in the European Union and does not rank them in relation to the thresholds consistent with SDG achievement. Thus, it can help countries benchmark their progress against that of their peers and not against the goal thresholds to be met by 2030 in order to achieve the SDGs. This can be a direction for future research.

\section{References}

Barkin D, Lemus B (2012) Understanding progress: a heterodox approach. Sustainability 5: 417-431.

Casula Vifell A, Soneryd L (2012) Organizing matters: how "the social dimension" gets lost in sustainability projects. Sustainable Development 20(1): 18-27.

Chan E, Lee K (2008) Critical factors for improving social sustainability of urban renewal projects. Social Indicators Research 85(2):243-256.

Clugston R (2011) Ethical framework for a sustainable world: Earth Charter Plus 10 
conference and follow up. Journal of Education for Sustainable Development 5: 173176.

Cuthill M (2009) Strengthening the social in sustainable development: developing a conceptual framework for social sustainability in a rapid urban growth region in Australia Sustainable Development 18(6): 362-373.

Dahl AL (2012) Achievements and gaps in indicators for sustainability. Ecological Indicators 17: 14-19.

Dempsey N, Bramley G, Powers S, Brown, C (2011) The social dimension of sustainable development: defining urban social sustainability. Sustainable Development 19(5): 289-300.

Di Franco G, Marradi A, (2013) Factor analysis and principal component analysis. Milano: FrancoAngeli.

Diaz-Sarachaga JM, Jato-Espino D, Castro-Fresno D (2018) Is the Sustainable Development Goals (SDG) index an adequate framework to measure the progress of the 2030 Agenda?. Sustainable Development 1-9.

Dobson A (2003) Citizenship and the Environment. New York: Oxford University Press.

Esping-Andersen G (1990) The Three Worlds of Welfare Capitalism. Cambridge: Polity Press.

Ferrera M (1996) The 'Southern model' of welfare in social Europe. Journal of European social policy 6(1): 17-37.

Giddings B, Hopwood B, O’Brien G (2002) Environment, economy and society: fitting them together into sustainable development. Sustainable Development 10: 187-196.

Goodland R (2002) Sustainability: human, social, economic and environmental. In T. Munn (Ed) Encyclopaedia of Global Environmental Change, 488-489. Hoboken, NJ: Wiley.

Gough I, Meadowcroft J, Dryzek J, Gerhards J, Lengfeld H, Marandya A, Ortiz R (2008) JESP symposium: climate change and social policy. Journal of European Social Policy 18(4):325-344.

Hák T, Janousková S, Moldan B (2016) Sustainable development goals: a need for relevant indicators. Ecological Indicators 60: 565-573.

Hawkes J (2001) The Fourth Pillar of Sustainability: Culture's Essential Role in Public Planning; Common Ground Publishing Pty Ltd in association with the Cultural Development Network (Vic): Victoria, Australia.

Hedlund-de Witt A (2011) The rising culture and worldview of contemporary spirituality: A sociological study of potentials and pitfalls for sustainable development. Ecological Economics 70: 1057-1065.

Helne T, Hirvilammi T (2015) Wellbeing and sustainability: a relational approach. Sustainable Development 23: 167-175.

Holden E, Linnerud K, Banister D (2016) The Imperatives of Sustainable Development. Sustainable Development 25(3): 213-226

Kemp R, Martens P (2007) Sustainable development: How to manage something that is subjective and never can be achieved? Sustainability: Science, Practice and Policy 3(2): 5-14.

Kemp R, Parto S, Gibson RB (2005) Governance for sustainable development: Moving from theory to practice. International Journal of Sustainable Development 8(1/2): 13-30.

Le Blanc D (2015) Towards integration at last? The sustainable development goals as a network of targets. Sustainable Development 23: 176-187.

Littig B, Grießler Griessler E (2005) Social sustainability: A catchword between political pragmatism and social theory. International Journal of Sustainable Development 8: 65-79. 
Morse S (2013) Indices and Indicators in Development: An Unhealthy Obsession with Numbers. London: Routledge.

Murphy K (2012) The social pillar of sustainable development: a literature review and framework for policy analysis Sustainability. Science, Practice and Policy 8(1): 1529.

Nurse K (2006) Culture as the Fourth Pillar of Sustainable Development. Commonwealth Secretariat: London, UK.

Pfahl S (2005) Institutional sustainability. International Journal of Sustainable Development 8: 80-96.

Riley J (2001) The indicator explosion: local needs and international challenges. Agriculture, Ecosystems \& Environment 87: 119-120.

Scott S (2007) Submission on the Report of the Department of Environment, Heritage and Local Government: Ireland's Pathway to Kyoto Compliance-A Review of the National Climate Change Strategy. Dublin: Economic and Social Research Institute.

Spangenberg JH (2002) Institutional sustainability indicators: An analysis of the institutions in Agenda 21 and a draft set of indicators for monitoring their effectivity. Sustainable Development 10: 103-115.

Spangenberg JH, Pfahl S, Deller K (2002) Towards indicators for institutional sustainability: Lessons from an analysis of Agenda 21. Ecological Indicators 2: 6177.

Stevens C, Kanie N (2016) The transformative potential of the Sustainable Development Goals (SDGs). International Environmental Agreements 16: 393-396

Thin N, Lockhart C, Yaron G (2002) Conceptualising Socially Sustainable Development. London: Department for International Development and World Bank.

Turkington R, Sangster K (2006) From housing to social mix: housing's contribution to social sustainability. Town and Country Planning 75(6):184-185.

UN (1982) A World Charter for Nature. New York: UN.

UN (1992) Earth Summit Agenda 21. The United Nations programme of action from Rio, New York: United Nations Department of Public Information,.

UN (1995) Copenhagen Declaration on Social Development. World Summit for Social Development, held in March 1995 in Copenhagen, Denmark http://www.un.org/.

UN (2002) Report of the World Summit on Sustainable Development, Johannesburg, South Africa, 26 August-4 Sept 2002. New York: UN.

UN (2012) Realizing The Future We Want for All, Report to the Secretary-General. UN System Task Team on the Post-2015 UN Development Agenda, New York.

Vavik T, Keitsch M (2010) Exploring relationships between universal design and social sustainable development: some methodological aspects to the debate on the sciences of sustainability. Sustainable Development 18 (5):295-305.

WCED (1987) Our Common Future. World Commission on Environment and Development. Oxford: Oxford University Press.

Wichaisri S, Sopadang A (2018) Trends and Future Directions in Sustainable Development. Sustainable Development 26: 1-17. 